This is a peer-reviewed, accepted author manuscript of the following research article: Walton, S., \& Ford, R. (2020). Easy or arduous? Practices, perceptions and networks driving lighting transitions from kerosene to solar in Vanuatu. Energy Research and Social Science, [101449]. https://doi.org/10.1016/j.erss.2020.101449

\title{
Easy or arduous? Practices, perceptions and networks driving lighting transitions from kerosene to solar in Vanuatu
}

\begin{abstract}
Sustainable transitions are often slow processes because the alignment of powerful institutions often takes time. Occasionally small yet significant transitions can surprise by being both widespread and quick. Such was the transition from kerosene to solar lighting in Vanuatu and as such makes a useful case study to explore and contribute towards the sustainable transitions body of knowledge. Drawing on social practice theory, we make sense at the individual participant level how the change was produced and reproduced in this Small Island Developing State (SIDS). An approach that moves away from a focus on the technology and instead works at the level of the practice, enables an understanding of how this material change did occur so rapidly. We identify the key elements of practices that enabled this transition to occur and found that across all elements of lighting practice in Vanuatu, the concept of 'ease' was important. As a result, we advocate for 'keeping it easy' and through the findings of this study illustrate how this might occur.
\end{abstract}

Keywords: solar lighting; practice theory; sustainable transitions; energy behaviour; Pacific; SIDS

Funding: This work was supported by Australian Aid [Agreement number 66554] 
This is a peer-reviewed, accepted author manuscript of the following research article: Walton, S., \& Ford, R. (2020). Easy or arduous? Practices, perceptions and networks driving lighting transitions from kerosene to solar in Vanuatu. Energy Research and Social Science, [101449]. https://doi.org/10.1016/j.erss.2020.101449

\section{Introduction}

Approximately 70\% of households in Small Island Developing States (SIDS) of the Pacific have no access to electricity $\left[{ }^{1}\right]$. Many are situated in small, remote and widely dispersed communities that often rely on kerosene for lighting, a fuel which requires significant and daily time commitments to procure and is often associated with fire risk, household air pollution and carbon dioxide emission hazards $[2,3,4,5,6]$. In Vanuatu there has been a substantive shift away from kerosene, partly this is due to the rapid transformation to pico-solar lighting. Such a quick transformation, i.e. 2-3-year period, runs counter to many of the discussions in developed countries that struggle to disrupt the locked-in energy systems that sustain and maintain a reliance on fossil fuels $\left[{ }^{7}\right]$. Considered alongside the slow and politically infused renewable energy debates in many countries globally, Vanuatu's rapid transition from a polluting to renewable fuel source is the kind of transitional story that many nations are aspiring to achieve. However, when contextualised, one can identify the differences in Vanuatu that have enabled this shift. For example, everywhere we travelled through Vanuatu people would approach us in their villages and ask for more solar lights; it seemed that solar was 'easy' for the way of life in the villages and helped the people meet their needs. Nevertheless, seeing such a shift led us to question how it had been achieved and to understand the social conditions that made it possible for this transition to occur (like for example Boamah \& Rothfuss ${ }^{8}$ ). We do not, however, see the lessons as being applicable universally but rather adding to our knowledge about understanding social conditions to make sense of technological transitions.

Energy transitions are complex processes combining social and technical factors $\left[{ }^{9}\right]$ that coalesce to shape practices at individual, group and community levels $\left[{ }^{10}\right]$. Understanding 
This is a peer-reviewed, accepted author manuscript of the following research article: Walton, S., \& Ford, R. (2020). Easy or arduous? Practices, perceptions and networks driving lighting transitions from kerosene to solar in Vanuatu. Energy Research and Social Science, [101449]. https://doi.org/10.1016/j.erss.2020.101449

change can be a straightforward process within simple systems with few actors. However, the transition from kerosene to solar lighting in Vanuatu encompassed change across technology, practices, business models, financial practices and culture -an assemblage of "complex and interwoven relations" $\left[{ }^{11}\right]$. It also required the co-operation between actors at various scales, including households, non-government organisations (NGO), various distribution partners, Government, Australian Aid and the World Bank $\left[{ }^{12}\right]$. Understanding such an energy transition calls for a theoretical approach that incorporates this multi-dimensionality as well as the structural change within which the transition is situated, and requires a framing that integrates the social and technical in a manner that helps explain the transition through being inclusive of the complexity of both of these systems. Understanding social, as well as technical drivers, is often neglected in studies on understanding clean energy systems $\left[{ }^{13}\right]$. Further, many studies of socio-technical transitions point to individuals to change practices, and often these changes can seem unattractive for the general population that has been saturated in a discourse of growth and consumerism $\left[{ }^{14}\right]$.

A big question then is how might a transition to a low carbon future occur in a way that involves widespread uptake of new systems of practice? Our experience in Vanuatu is one example of a sustainable transition from which the lessons are not just applicable for developing island states. In developed countries researchers are exploring how to transition to low-carbon economies by exploring the conditions of possibility for change. We found that the increasing use of portable lighting in Vanuatu is deeply embedded in many everyday contexts and practices. It is, as Shove \& Walker suggest, embedded in "domains of everyday life" $\left[{ }^{15}\right]$, and is what "people do" $\left[{ }^{16}\right]$ for example eating dinner, engaging in social activities, walking between home, work and the nakamal (the area where the males in the village meet 
This is a peer-reviewed, accepted author manuscript of the following research article: Walton, S., \& Ford, R. (2020). Easy or arduous? Practices, perceptions and networks driving lighting transitions from kerosene to solar in Vanuatu. Energy Research and Social Science, [101449]. https://doi.org/10.1016/j.erss.2020.101449

to drink the traditional drink - kava). Indeed, lighting as a practice is enabled, constrained and contextualised by the underlying activities of everyday life, which provide points (e.g. those surrounding cooking, drinking) for systems and behaviour to interact $\left[{ }^{17}\right]$. As such we find that Social Practice Theory (SPT) offers a perspective to conceptualise the various processes and rituals of daily life that underpin such practices and supports enquiry into how change may occur [ 18192021 . In addition, SPT enables an exploration of transition that moves beyond linear explorations of attitude, behaviour and choice in individual decision-making and diffusion of technology, to situating the analysis around the practice $\left[{ }^{22}\right]$. Thus the focus of this paper (and SPT in general) is on practices that are part of everyday routines, the elements that contribute to these practices, and the way in which they are embedded in society.

Social Practice Theory (SPT) draws on numerous theoretical traditions (for example the work of Bourdieu, Giddens, LaTour). The work of Bourdieu and Giddens is interested in the ways that patterns of behaviour are linked with underlying beliefs about the social world $\left[\begin{array}{ll}23 & 24 \\ 25\end{array}\right]$. Their work was built on by Schatzki $\left[{ }^{26}\right]$, who emphasised the importance of rules, desires, beliefs, and expectations in structuring practice and Reckwtiz $\left[{ }^{27} 28\right]$, who integrated the concept of material objects in building and maintaining practices, as influenced by actor network theory $\left[{ }^{29}\right]$.

We adopt a recent approach to SPT, developed in the work of Elizabeth Shove, that pays attention to the material culture and the ways in which social life practices are enabled and (re)produced through the relationship between these two, and how theories of practice can support an understanding of change and support societal transitions [ $\left[\begin{array}{lll}30 & 31 & 32\end{array}\right]$. Shove suggests that while there have been research traditions examining the concept of consumption ( see for example the work of $\mathrm{Du} \mathrm{Gay}^{33}$ ), the construction of identity through consumption 
This is a peer-reviewed, accepted author manuscript of the following research article: Walton, S., \& Ford, R. (2020). Easy or arduous? Practices, perceptions and networks driving lighting transitions from kerosene to solar in Vanuatu. Energy Research and Social Science, [101449]. https://doi.org/10.1016/j.erss.2020.101449

$\left[{ }^{34}{ }^{35}\right]$ and the ways in which material artefacts are used, there has been little work that theoretically analyses the relationship between material artefacts and practices to understand the production and reproduction of social life $\left[{ }^{36}\right]$. Shove's work on Nordic walking $\left[{ }^{37}\right]$, transitions $\left[{ }^{38}\right]$ and comfort $\left[{ }^{39}{ }^{40}\right]$ gives insight into how to analyse at the level of a practice and how that enables an understanding of transitions - that is, the way in which both material artefacts and the social life might change.

Drawing on SPT we suggest that to understand the lighting energy transition in Vanuatu, it is important to explore how lighting as a practice is sustained and reproduced, and how practice can help understand energy transitions when new configurations may become dominant $\left[{ }^{41} 4^{42}\right]$. The use of SPT as an organising framework helps to organise our findings and tell a richer story of transition involving multiple actors at multiple scales, generating greater insight into the rapid transition from kerosene to solar lighting in rural Vanuatu.

\section{Methods}

The overall approach to this research is qualitative in nature to enable an in-depth exploration of the meanings that people attributed to lighting practices, the skills and competencies associated with the use of lighting, and their perspectives surrounding lighting technology (both old and new). The approach coupled semi-structured interviews and ethnographic observation with data from a series of household surveys and census data to provide a holistic perspective around the transition from kerosene to solar lighting. Figure 1 depicts the timeline of events, outlining when the Lighting Vanuatu project began, and identifying when the surveys and field work occurred. 
This is a peer-reviewed, accepted author manuscript of the following research article: Walton, S., \& Ford, R. (2020). Easy or arduous? Practices, perceptions and networks driving lighting transitions from kerosene to solar in Vanuatu. Energy Research and Social Science, [101449]. https://doi.org/10.1016/j.erss.2020.101449

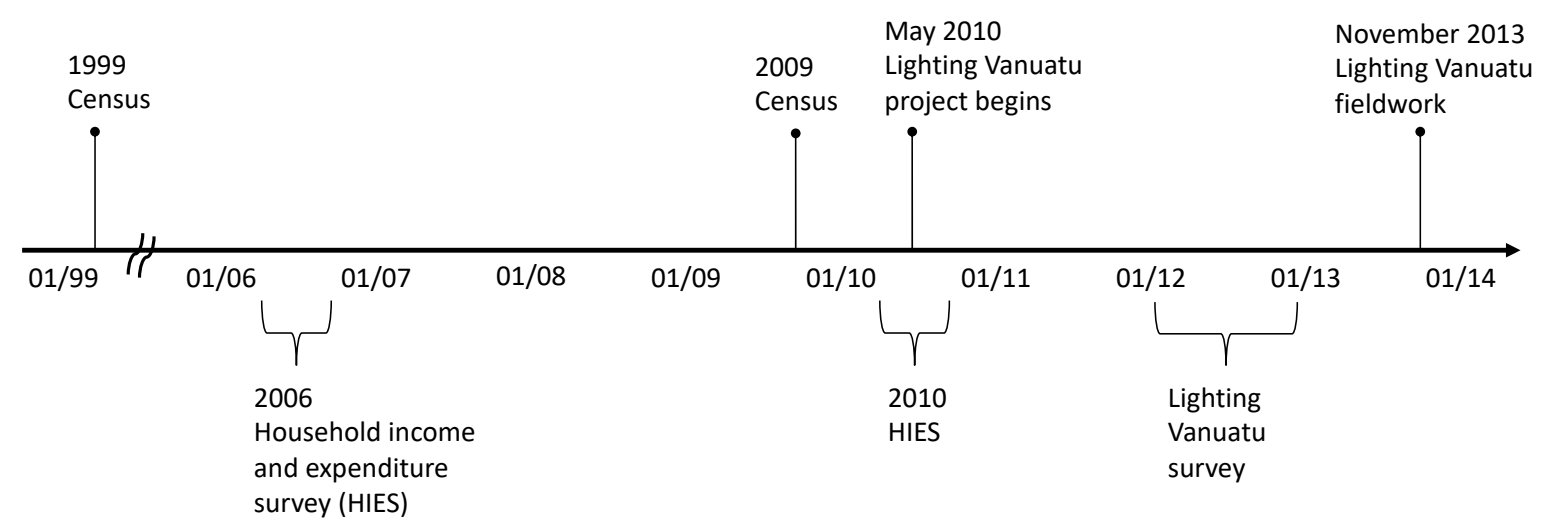

Figure 1: Timeline for Lighting Vanuatu project and data gathering exercises

\subsection{Interviews}

Semi-structured interviews were conducted during a two-week period in Vanuatu with a subset of beneficiary households and communities of the Lighting Vanuatu project. Interviews were designed to elicit information about the context, links and changes between lighting technology and family and social practices. The interviews were conducted approximately 2 years after the introduction of the solar lights via the Lighting Vanuatu project. The questions were organised around the following topics:

1. Contextual information was sought to gain an understanding of the participants and their general patterns of everyday life.

2. Questions were asked to get an insight into the material culture around lighting technologies owned and used by the households, and the extent to which a technological shift in lighting solutions has been cultivated. These questions included issues surrounding the decision to purchase (or not) solar lights, such as where they heard about the lights, if they knew anyone else using solar, and what the key economic differences were found to be. 
This is a peer-reviewed, accepted author manuscript of the following research article: Walton, S., \& Ford, R. (2020). Easy or arduous? Practices, perceptions and networks driving lighting transitions from kerosene to solar in Vanuatu. Energy Research and Social Science, [101449]. https://doi.org/10.1016/j.erss.2020.101449

3. Questions were also aimed to elicit a fuller understanding of how any shift in technology has impacted on family practices and daily life, especially around energy related practices in the home; where and when the lights are used, how has this varied between the old and new lighting technology and how the lights are recharged.

4. Questions aiming to probe shifts in norms and aspirations around lighting and other solar technologies (e.g. photovoltaic panels) were asked to obtain an understanding how communities may want to use solar technologies in the future. Has their experience to date affected their appetite for more solar lamps or for bigger systems capable of delivering power?

The household interviews were carried out in Bislama (the local language) with trained translators or enumerators initially dealing directly with villagers and noting responses to the pre-developed questions. However, after only a handful of interviews and listening intently, we could pick up the language and work with the enumerators to conduct the interviews in a more semi-structured manner. For the clear majority of the interviews the researchers were able to have a role in the generation of the data. Distribution chain interviews were also held with the NGOs involved in the project and other private renewable energy businesses to understand their role in the Lighting Vanuatu project and the shift to solar lighting. These seven interviews were mostly recorded in the participants' place of work (one of the NGOs interviews was conducted in a hotel) and on average they lasted 40 minutes, were all conducted in English and transcribed word for word. Observational fieldnotes were generated from visiting trader stores and any other businesses/shops selling solar lights. 
This is a peer-reviewed, accepted author manuscript of the following research article: Walton, S., \& Ford, R. (2020). Easy or arduous? Practices, perceptions and networks driving lighting transitions from kerosene to solar in Vanuatu. Energy Research and Social Science, [101449]. https://doi.org/10.1016/j.erss.2020.101449

Further to these interviews other stakeholders were interviewed as part of the process to understand the implications of the project, for example, interviews were held with representatives from the World Bank, NZ Aid and Telecom Vanuatu Ltd. These 8 interviews were conducted in English usually in the participants' place of work and transcribed wordfor-word.

In total 6 islands were visited with at least 3 villages selected as a base for conducting interviews on each island. Vanuatu has around 83 islands, many of which are small and uninhabited. The islands were chosen using a remoteness index created by a local development consultant. The remoteness ranking accounted for both flight and shipping schedules to each island - Efate and Espiritu Santo are ranked at 1; those with regular (daily or more) contact with either Port Vila or Luganville are ranked at 2; a Ranking of 3-4 reflects services 2 or more times per week; while a Ranking of 6 and 7 reflects services of once per week or less. The islands were chosen to represent and exemplify each index of remoteness from the capital Port Vila. The 6 islands included in the study are Tanna (10 interviews across 4 villages), Efate ( 8 interviews across 2 villages), Malekula (10 interviews across 3 villages), Epi (11 interviews across 2 villages), Espiritu Santo ( 2 focus groups in 1 village) and Mota Lava (2 focus groups in 1 village).

Upon arrival on the Island the research team needed to seek approval from the Island equivalent of a Mayor/Head of the Council. At this point the choice of villages would be discussed and a plan developed. This was often a loose plan as there may not be people in the village when we arrived or we may get invited to another village too. Villages were often not far apart from one another and it could be hard to tell when we walked from one village and arrived in another. 
This is a peer-reviewed, accepted author manuscript of the following research article: Walton, S., \& Ford, R. (2020). Easy or arduous? Practices, perceptions and networks driving lighting transitions from kerosene to solar in Vanuatu. Energy Research and Social Science, [101449]. https://doi.org/10.1016/j.erss.2020.101449

Visits to the villages began with introductions and meeting the chief, followed by a guided tour. After this, the villagers would assemble at a village meeting point which was often under a large Banyan tree. A large focus group was then conducted with some general questions, followed by individual interviews with a selection of villagers, typically around 6 . However sometimes the islands and villages were just so small that focus groups only were carried out. In total there were 43 documented interviews and focus groups carried out in this style.

\subsection{Observation}

A significant part of the research in the field could be termed 'ethnographic' meaning that it involved immersion by observation and participation in the cultural field of the investigation $\left[{ }^{43}{ }^{44}\right]$. We use the term ethnography to depict a method that Geertz borrowed from Ryle, famously termed "thick description" $\left[{ }^{45}\right]$ meaning that data in an ethnographic method involves descriptions of complex human interactions in complex contexts examined as part of the field research. It is 'thick' in terms of being densely rich data. While we use an ethnographic method, we have not adopted a traditional ethnographic realist position in this research, i.e. a search for an objective reality or a "passive contemplation of existence" $\left[{ }^{46}\right]$. Rather, we adopted an approach of acknowledging multiple subjectivities and meanings $\left[{ }^{47}\right]$ capturing the ways in which people make sense of the world around them. Our research journey included key aspects described by Fetterman $\left[{ }^{48}\right]$ as culture, holistic perspective, contextualisation, multiple realities, non-judgemental orientation, symbol \& ritual.

Field notes were made at the time of immersion. Each researcher made notes during interviews and focus groups, as well as at the end of each village visit and the end of each 
This is a peer-reviewed, accepted author manuscript of the following research article: Walton, S., \& Ford, R. (2020). Easy or arduous? Practices, perceptions and networks driving lighting transitions from kerosene to solar in Vanuatu. Energy Research and Social Science, [101449]. https://doi.org/10.1016/j.erss.2020.101449

day. In addition, all researchers kept diaries that captured their personal thoughts, feelings and experiences. All the data was shared at the conclusion of the field work. Field notes consisted of "accounts describing experiences and observations the researcher has made while participating in an intense and involved manner" $\left[{ }^{49}\right]$ and are an important part of the ethnographic research journey. The notes aimed to be reflective on participant voice, physical environs, behaviours and each researcher's own thoughts, which were sometimes challenged through the experiences we all had.

\subsection{Survey}

The survey was conducted throughout 2012, the last year of the solar lighting programme, using a paper-based enumerator-administered questionnaire, initially distributed by US Peace Corps volunteers during the first half of 2012. To facilitate a greater response rate, Youth Challenge Vanuatu volunteers, local churches and the Australian Youth Ambassadors were also engaged from July 2012 onwards.

The purpose of this survey was to generate baseline knowledge about the uptake and usage patterns of the lamps across Vanuatu's islands, and to inform the development of more detailed interview questions posed during the field work undertaken in November 2013 (described in Section 2.1).

Respondent households were selected through a three-stage cluster sampling process. In the first stage the 'survey universe' $(\mathrm{N})$ was defined as the number of rural households (outside of Port Vila and Luganville), which is estimated to be 167,357 people or 34,866 households. In the second stage, islands were chosen for sampling based on the remoteness ranking described previously. In the third stage, enumerators were responsible for 
This is a peer-reviewed, accepted author manuscript of the following research article: Walton, S., \& Ford, R. (2020). Easy or arduous? Practices, perceptions and networks driving lighting transitions from kerosene to solar in Vanuatu. Energy Research and Social Science, [101449]. https://doi.org/10.1016/j.erss.2020.101449

selecting communities/villages from comprehensive lists of village names for each of the sampled islands, taking into account logistical considerations such that the villages could be visited within the required timeframe.

The required number of households from each of the sampled islands was determined on a proportional basis. The unit of analysis for this survey is a 'rural household'. For the purposes of this study a household is defined as the group of people that 'eat from the same pot'. The survey is only administered in households that currently own or use a solar powered light. Enumerators were to ask first for households with solar lights then ask for participation based on this criterion. They were to choose a certain number of households per village or Island dependent on the population distribution.

The type of questions consisted of demographics, household and house profile e.g. the number of people, rooms, lights and lighting sources. Then there were a series of questions about the solar lights including, how many were owned, the financial impact of buying the lamp, how people came to know about the lights, from whom did they purchase the lights, the date and cost, the main use of the light and who mainly uses the light, how long the light is used on average, have they repaired the lights, are they moving to more solar and what do they least like or most like about the solar lamps (the full survey instrument is provided in the supplementary material).

In total 1,427 survey responses were included in the analysis. This comprised of data from 193 villages across 19 islands (see Table 1). 
This is a peer-reviewed, accepted author manuscript of the following research article: Walton, S., \& Ford, R. (2020). Easy or arduous? Practices, perceptions and networks driving lighting transitions from kerosene to solar in Vanuatu. Energy Research and Social Science, [101449]. https://doi.org/10.1016/j.erss.2020.101449

Table 1: Villages covered by the Lighting Vanuatu survey

\begin{tabular}{|c|c|c|c|c|c|}
\hline Island & $\begin{array}{l}\text { Remoteness } \\
\text { ranking }\end{array}$ & $\begin{array}{l}\text { Census } \\
\text { population }\end{array}$ & $\begin{array}{l}\text { No. of } \\
\text { surveys }\end{array}$ & $\begin{array}{l}\text { No. of } \\
\text { villages }\end{array}$ & $\begin{array}{l}\text { Major surveyed villages } \\
\text { (generally } \mathrm{n}>10 \text { survey } \\
\text { respondents) }\end{array}$ \\
\hline Efate & 1 & 65829 & 174 & 11 & $\begin{array}{l}\text { Saama, Natapau, } \\
\text { Magaliliu, Tanoliu, } \\
\text { Eratap, Eton, Takara }\end{array}$ \\
\hline Santo & 1 & 39606 & 375 & 35 & $\begin{array}{l}\text { Arantoa, Banbab, Beleru, } \\
\text { Hog Harbour, Kolei, } \\
\text { Malao, Mavunlep, Naone, } \\
\text { Natawa, Pepsi, Sara, } \\
\text { Winsao }\end{array}$ \\
\hline Malakula & 2 & 22934 & 32 & 2 & Dravail, Lamap \\
\hline Tanna & 2 & 28799 & 359 & 65 & $\begin{array}{l}\text { Epakel, Iarkei, Lahtapu, } \\
\text { Lemakaun, Lapangtawa, } \\
\text { Laweane, Learfi, Lenakel. } \\
\text { Lounu, Port Resolution }\end{array}$ \\
\hline Ambrym & 3 & 7275 & 12 & 1 & Toak \\
\hline Epi & 3 & 5207 & 19 & 3 & Alack \\
\hline $\begin{array}{l}\text { Pentecost } \\
\text { Island }\end{array}$ & 3 & 16843 & 21 & 7 & Nafaranguit, Vanmelang \\
\hline Aore & 4 & 556 & 26 & 7 & $\begin{array}{l}\text { Siro, Nawaswas, Port } \\
\text { Latoir }\end{array}$ \\
\hline
\end{tabular}


This is a peer-reviewed, accepted author manuscript of the following research article: Walton, S., \& Ford, R. (2020). Easy or arduous? Practices, perceptions and networks driving lighting transitions from kerosene to solar in Vanuatu. Energy Research and Social Science, [101449]. https://doi.org/10.1016/j.erss.2020.101449

\begin{tabular}{|c|c|c|c|c|c|}
\hline Maewo & 4 & 3569 & 13 & 1 & Naviso \\
\hline Malo & 4 & 4273 & 53 & 9 & Tanmeal, Nanuk \\
\hline Nguna & 4 & 1255 & 42 & 14 & Malaliu, Taloa \\
\hline Paama & 4 & 1627 & 20 & 1 & Tahi \\
\hline Pele & 4 & 321 & 10 & 5 & Piliura \\
\hline Makira & 5 & 106 & 14 & 1 & Malakoto \\
\hline Vanualava & 5 & 1933 & 89 & 14 & $\begin{array}{l}\text { Mosina, Sola, Vatop, } \\
\text { Vureas }\end{array}$ \\
\hline Buninga & 6 & 144 & 10 & 6 & No major village \\
\hline Motolava & 6 & 1451 & 130 & 9 & $\begin{array}{l}\text { Avar, Demsas, } \\
\text { Nerenigman, Qeremande, } \\
\text { Rah, Toutoulau, }\end{array}$ \\
\hline Aniwa & 7 & 341 & 14 & 1 & Ikaukau \\
\hline Moto & 7 & 683 & 1 & 1 & No major village \\
\hline x) Mis & - & - & 22 & - & - \\
\hline Total & - & 202752 & 1436 & 193 & - \\
\hline
\end{tabular}

In total 1436 survey responses were collected, however 9 had to be excluded from analysis due to incomplete responses. Of the 1427 surveys included for analysis purposes, fifty-two percent were completed by male respondents. Most respondents were aged between 21-40 years and most had completed primary school but $11.2 \%$ were illiterate. Only 94 participants were connected to an electricity grid. 
This is a peer-reviewed, accepted author manuscript of the following research article: Walton, S., \& Ford, R. (2020). Easy or arduous? Practices, perceptions and networks driving lighting transitions from kerosene to solar in Vanuatu. Energy Research and Social Science, [101449]. https://doi.org/10.1016/j.erss.2020.101449

\subsection{Analysis}

The analysis was largely interpretative We were keen to bring out participant perceptions and use participant voice where possible to understand this transition. A thematic analysis was applied to the information collected from the beneficiary household and community interviews to draw out the significant themes and codes from the data. The aim of the thematic analysis was to provide a rich description of the changes in household and community practices associated with the new lighting technology. Both researchers independently thematically analysed the qualitative data before cross referencing the themes which produced four initial main themes. These themes are outlined in Table 2.

\section{Table 2: Initial thematic analysis}

\begin{tabular}{|l|l|}
\hline \multicolumn{1}{|c|}{ Theme } & \multicolumn{1}{c|}{ Description } \\
\hline $\begin{array}{l}\text { 'Easy' as an } \\
\text { outcome }\end{array}$ & Having a portable solar light simply made life a little easier. \\
\hline Solar expectations & $\begin{array}{l}\text { "What else but solar!" The future trajectory of energy and } \\
\text { lighting in Vanuatu was discussed as being solar. }\end{array}$ \\
\hline $\begin{array}{l}\text { Subsistence and cash } \\
\text { economy }\end{array}$ & $\begin{array}{l}\text { The key benefit of the portable solar lights identified by } \\
\text { nearly every respondent was the cost saving. For remote rural } \\
\text { communities a lighting source involving a one time capital } \\
\text { expense was preferable to the ongoing variable cost of } \\
\text { kerosene fuel. }\end{array}$ \\
\hline $\begin{array}{l}\text { Circulation, } \\
\text { communication \& } \\
\text { community }\end{array}$ & $\begin{array}{l}\text { The informal networks already existing within Vanuatu } \\
\text { enabled a circulation of knowledge and people through the } \\
\text { many islands resulting in the lights being distributed widely. } \\
\text { Using known NGOs with already established networks in a } \\
\text { country where networks of people are key communication } \\
\text { channels was a major key to the success of this transition. }\end{array}$ \\
\hline
\end{tabular}

The interpretation of these themes, and the fieldwork in general, was sensitised by the SPT and in particular by the work of Shove and Pantzar $\left[{ }^{50}\right]$ and the analysis process they 
This is a peer-reviewed, accepted author manuscript of the following research article: Walton, S., \& Ford, R. (2020). Easy or arduous? Practices, perceptions and networks driving lighting transitions from kerosene to solar in Vanuatu. Energy Research and Social Science, [101449]. https://doi.org/10.1016/j.erss.2020.101449

used to understand Nordic walking. We took the above themes, which represent the key statements made by participants about their everyday practices with the lights, and coded them against the elements of practice, skills/competence, material and symbolic meanings. We also found further elements that we identify as part of the system of practice which are discussed in the results in terms of how they help explain the practices. Additionally, a contextual analysis of the data examining not only what participants said but also what enabled them to make particular statements in particular ways (i.e. why some statements were constructed in a certain way and understood in a common-sense manner) enabled further exploration of the energy transition $\left[{ }^{51}\right]$ and added context to the results. Although this approach may seem to be just about words and language, it allowed us to explore meanings that may otherwise be taken for granted (see for example Laclau \& Mouffe, ${ }^{52}$ ) which is a key part of SPT.

Data from the surveys was used to contextualise the findings (e.g. by demonstrating the rapid uptake of solar lanterns across a wider range of islands and villages than those in which interviews and observational research took place) and to support the data arising from the interviews in terms of understanding (across a wider range of households) what influenced households to purchase their lights, how the lights were primarily used, and what key changes had occurred in their wider lifestyle since getting the lights. The interpretation of the results is presented in the following section.

\section{Results and discussion}

In this section we present empirical findings from our analysis of lighting practices, drawing from all three data collection streams (survey, interviews and observation) and using participant voice to (re)present the practices from the perspective of the consumer. We focus 
This is a peer-reviewed, accepted author manuscript of the following research article: Walton, S., \& Ford, R. (2020). Easy or arduous? Practices, perceptions and networks driving lighting transitions from kerosene to solar in Vanuatu. Energy Research and Social Science, [101449]. https://doi.org/10.1016/j.erss.2020.101449

particular attention on both the practice itself and on those "elements as ingredients of practice" $\left[{ }^{53}\right]$. Therefore the results represent the various elements that create the system of solar lighting practice, in other words, the elements that enable the practice of lighting in Vanuatu to be what it is today. These elements are important to understand so we will examine how they configure to create the system of practice of lighting in Vanuatu. We start with the context of Vanuatu and then explore the elements involved in the practice of solar lighting.

\subsection{The context of lighting in Vanuatu}

Vanuatu is comprised of 83 islands supporting a population of approximately 250,000 people, of which fewer than $30 \%$ are connected to an electrical power grid. This infrastructure is limited to areas of Port Vila and Luganville, and while some rural communities do have access to generators they are generally found to be expensive to run and are not used frequently. Even the people living in those houses connected to the grid infrastructure often choose not to use energy in this way due to the unreliability of supply.

The lifestyle in rural Vanuatu tends to be an outdoor one; many people live in homes that have 2 or 3 rooms as well as a separate area for food preparation and another for washing that are often not connected to the main building. There are also toilets that may be shared with other families and are separated by a short walk from the main buildings. In addition, there is a social element within most rural communities, each village having a traditional meeting place used for community gatherings and ceremonies. Many also have a nakamal, where men (and sometimes women, but not often) can congregate for the preparation and drinking of kava. 
This is a peer-reviewed, accepted author manuscript of the following research article: Walton, S., \& Ford, R. (2020). Easy or arduous? Practices, perceptions and networks driving lighting transitions from kerosene to solar in Vanuatu. Energy Research and Social Science, [101449]. https://doi.org/10.1016/j.erss.2020.101449

As the sun sets relatively early throughout the year $5: 20 \mathrm{pm}$ in winter and $6: 20 \mathrm{pm}$ in summer) people are frequently eating dinner, engaged in social activities, or moving around different parts of their home or between their homes and other buildings in the village after dark. Due to the lack of access to electricity in rural Vanuatu, combined with the early hour of sunset throughout the year, portable lighting has played a role within these communities for some time. For example, in an 18-month ethnography conducted nearly 15 years ago, New Zealand anthropologist James Patrick Taylor describes the use of portable lamps:

Houses with corrugated iron mixed with those of more familiar concrete blocks, some emitting the glow of an electric light or more softly-toned hurricane lamps. People were out walking, on their way home from work or off to drink kava at one of the many nakamal (kava bars) whose proprietors had hung out kerosene lamps, signalling that their kava was ready $\left[{ }^{54}\right]$.

Given the detrimental environmental and health impacts associated with kerosene lighting, the Australian Aid Governance for Growth Programme funded a 2-year Lighting Vanuatu project. This project, which was initiated in 2010, had a primary objective of increasing access to portable solar lanterns for rural Vanuatu communities in an effort to reduce their dependency on kerosene as the primary fuel source for household lighting. To achieve this goal, the project offered a supply-side subsidy for two Vanuatu NGOs (called ACTIV and VANREPA) to support the distribution of 24,000 solar lights mainly to rural areas. The subsidy was aimed at improving the bulk purchasing power by the NGOs to reduce the price of the imported solar lights at the household level.

An analysis of the program (TBA after review process, 2014) indicates that the Lighting Vanuatu project has been successful in enabling the uptake and awareness of portable 
This is a peer-reviewed, accepted author manuscript of the following research article: Walton, S., \& Ford, R. (2020). Easy or arduous? Practices, perceptions and networks driving lighting transitions from kerosene to solar in Vanuatu. Energy Research and Social Science, [101449]. https://doi.org/10.1016/j.erss.2020.101449

solar lighting products, and highlights that the transition from kerosene lamps to solar throughout the islands of Vanuatu was both clear and ubiquitous. The Lighting Vanuatu project exceeded its target of distributing 24,000 solar lights, with the independent completion report estimating that more than 55,000 solar lanterns were distributed between 2010 and 2013.

Our observations during field work also suggest that Vanuatu's lighting culture has observably changed since 2010 when kerosene was the dominant lamp technology. The visual presence of solar lights has replaced the softly-toned kerosene lamps. In cities, portable solar lights hold a ubiquitous and prominent space in the window displays of many retail shops. A visual stocktake of shops in Port Vila and Luganville confirm that nearly every Chinese shop ${ }^{1}$ and most daily goods stores prominently display portable solar lighting products, highlighting their popularity and demand in the retail space. Portable solar lights are even more prominent in rural villages where they are readily visible, found either hanging on the houses or placed on grassy clearings to gather the sun's rays. The lights that beckon customers to the kava bars are now often solar, not kerosene. In fact, where kerosene lamps were found, they were often abandoned and broken.

\subsection{The practice of lighting in Vanuatu}

\subsection{Material equipment: changing technology to solar}

The findings from the three data streams indicate a huge shift in "lighting stuff" (i.e. the materials and technologies used for lighting) has emerged in recent years. Increased use of solar has occurred concurrently with a massive reduction in the use of kerosene for lighting.

\footnotetext{
${ }^{1}$ This is a local term for shops run by Chinese people that tend to sell cheaper products for the local market.
} 
This is a peer-reviewed, accepted author manuscript of the following research article: Walton, S., \& Ford, R. (2020). Easy or arduous? Practices, perceptions and networks driving lighting transitions from kerosene to solar in Vanuatu. Energy Research and Social Science, [101449]. https://doi.org/10.1016/j.erss.2020.101449

National Statistics Office (NSO) data ${ }^{2}$ for Vanuatu indicates that over $90 \%$ of households relied on kerosene for lighting in 1996 and in 2009 this figure was still over 70\%. By 2010 the Household Income and Expenditure Survey indicated that this had dropped to about 50\% and by 2013, the survey data, field observations and stakeholder interviews indicated that less than $10 \%$ of households were using kerosene for lighting. The reduction in kerosene use in rural areas appeared to be relatively uniform across the country, showing little significant regional variation.

Solar lighting on the other hand, rose from about $4 \%$ in 2009 to about $20 \%$ in 2010 and has continued to rise ever since; in our survey conducted in 2012, 1,242 of the 1,251 respondents claimed to own a solar light, and the pervasiveness of this new technology was certainly evident in the villages visited during the 2013 field study. Even in villages with access to grid electricity, the solar lights were used extensively in activities such as fetching water, fishing at night or walking between villages. To further explore the factors that gave rise to the shift in lighting technology, we reflect on the other two elements surrounding lighting practices, namely "images" and "competence".

\subsubsection{Images and symbolic meanings associated with the practice of solar lighting}

There is no doubt that the technological shift to solar has resulted in shifting perceptions around both lighting and solar more generally. This shift has emerged as a result of the ubiquitous nature of the lights, the convenience they add to rural life and the cultural norms already aligned. Symbolically the lights were more than just solar lights - they represented the future and progress, a sense of freedom, and were aligned with householders'

\footnotetext{
${ }^{2}$ NSO data includes the 1999 Census; the 2006 Household Income and Expenditure Survey (HIES); the 2009 Census; and the 2010 HIES.
} 
This is a peer-reviewed, accepted author manuscript of the following research article: Walton, S., \& Ford, R. (2020). Easy or arduous? Practices, perceptions and networks driving lighting transitions from kerosene to solar in Vanuatu. Energy Research and Social Science, [101449]. https://doi.org/10.1016/j.erss.2020.101449

belief systems. As such there was no need for a 'hard sell' of the lighting - it just made sense in terms of how the participants went about their everyday life.

People in the villages talked about the sense of freedom that solar lights provided. Typically, they could last all night if they had been charged during the day, and this freed families from the previous daily practices around collecting firewood for cooking and/or lighting and purchasing kerosene. Women discussed the reductions in household tension due to these changes; previously the purchase of kerosene was a task coordinated by the women but requiring their husbands to provide them with money to do so, a daily cause of contention. In addition, the fact that the solar lights were cheaper (read free) to run meant that the length of time they were on was not monitored in the same way that a candle or kerosene lamp had been. Comments indicated that this gave a sense of freedom in terms of being able to just use them when they were needed and wanted.

Once they had purchased and used a solar light, the large majority of people interviewed expressed the expectation that there was no going back to kerosene or gas. For instance, during a household interview in Nerenigman village on Mota Lava (November 21, 2013), one respondent expressed this sense of progression by stating, "If we had to go back to kerosene we would be embarrassed." The perception being that anything other than solar would be like falling backwards, even to the point of stigmatisation for those who still used it, or as another respondent from a focus group on Mota Lava (November 21, 2013) recounted, "If we see someone using kerosene we laugh, it's like they're stuck in the past."

Solar energy was closely associated with progress, to the degree that in the vast majority of interviews, alternative energy options were rarely discussed. Alternative energy sources were perceived as being 'backwards', or in some instances just plain 'bad', even if 
This is a peer-reviewed, accepted author manuscript of the following research article: Walton, S., \& Ford, R. (2020). Easy or arduous? Practices, perceptions and networks driving lighting transitions from kerosene to solar in Vanuatu. Energy Research and Social Science, [101449]. https://doi.org/10.1016/j.erss.2020.101449

the participants themselves had to rely on torches when the solar light had broken or following a period without sun. As another respondent from Emua village on Efate (November 17, 2013) exclaimed, "What else but solar!"

This perspective of solar spread very quickly through the communities, with most people $(68.9 \%)$ finding out about the existence of solar lights from family and friends. Family and friends were also reported as having the greatest influence on the purchase decision, as shown in Figure 2 and this was reflected in the conversations with households, where it was frequently reported that they purchased their light because they saw their family member/neighbour with one and wanted one too. Other households liked their solar lights so much they actively encouraged others to purchase them.

"I want to have more solar light. I tell my friends and family that they have to get solar light”. Respondent from Burumba in Epi (November 19. 2013). 
This is a peer-reviewed, accepted author manuscript of the following research article: Walton, S., \& Ford, R. (2020). Easy or arduous? Practices, perceptions and networks driving lighting transitions from kerosene to solar in Vanuatu. Energy Research and Social Science, [101449]. https://doi.org/10.1016/j.erss.2020.101449

Figure 2: Greatest influence ${ }^{3}$ on participants' purchase decision (data from 2012 survey)

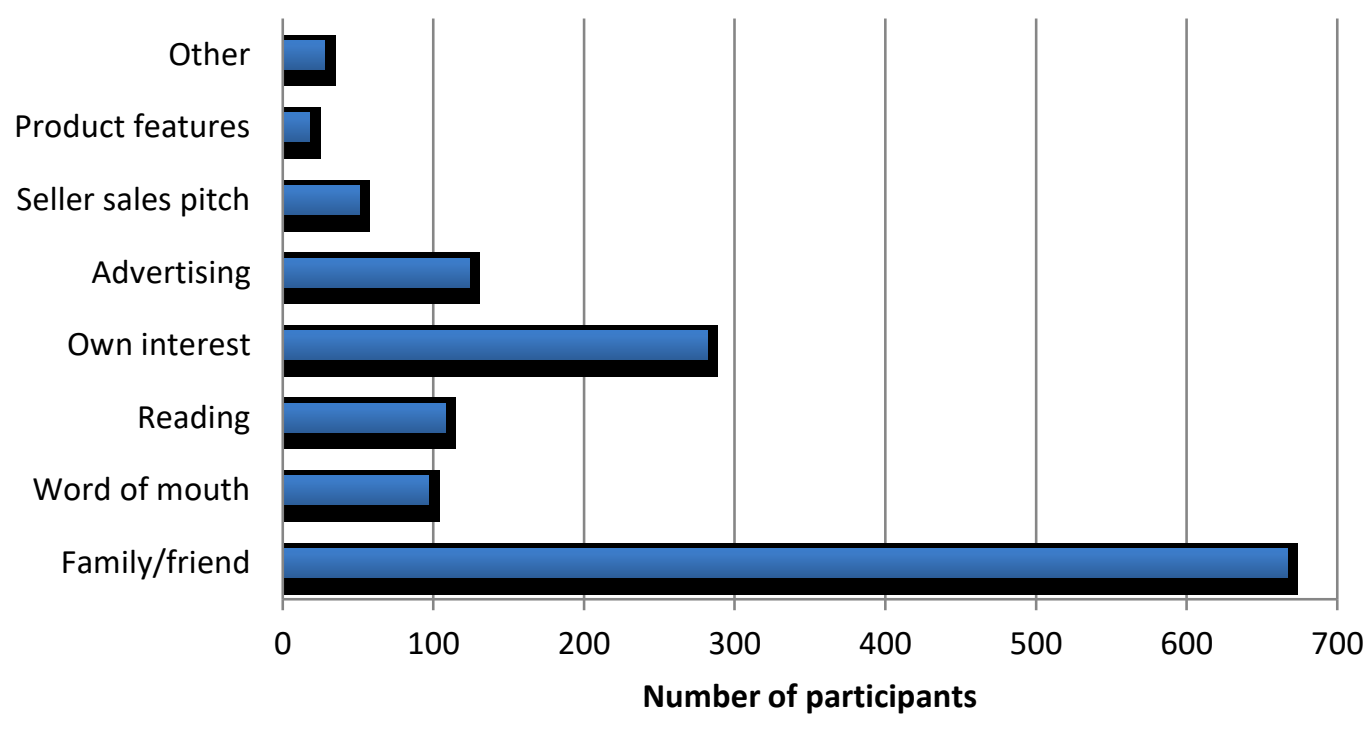

The traditional kerosene lamps were already disliked due to the regular expense associated with purchasing the fuel (both financial and time), and the range of negative impacts on health and safety which participants mentioned. The predisposition against kerosene combined with the financial benefit of solar (paying only once for the lamp and then charging it for free using sunlight) and smart marketing tapping into prevalent religious beliefs (see Figure 3) provided the push that most households needed to purchase solar lights.

22. ${ }^{3}$ Participants were asked "What had the greatest influence on your purchase decision?" and asked to choose one option from the set of answers shown in Figure 2. 
This is a peer-reviewed, accepted author manuscript of the following research article: Walton, S., \& Ford, R. (2020). Easy or arduous? Practices, perceptions and networks driving lighting transitions from kerosene to solar in Vanuatu. Energy Research and Social Science, [101449]. https://doi.org/10.1016/j.erss.2020.101449

\section{Figure 3: Solar lighting advertisements observed during field study}

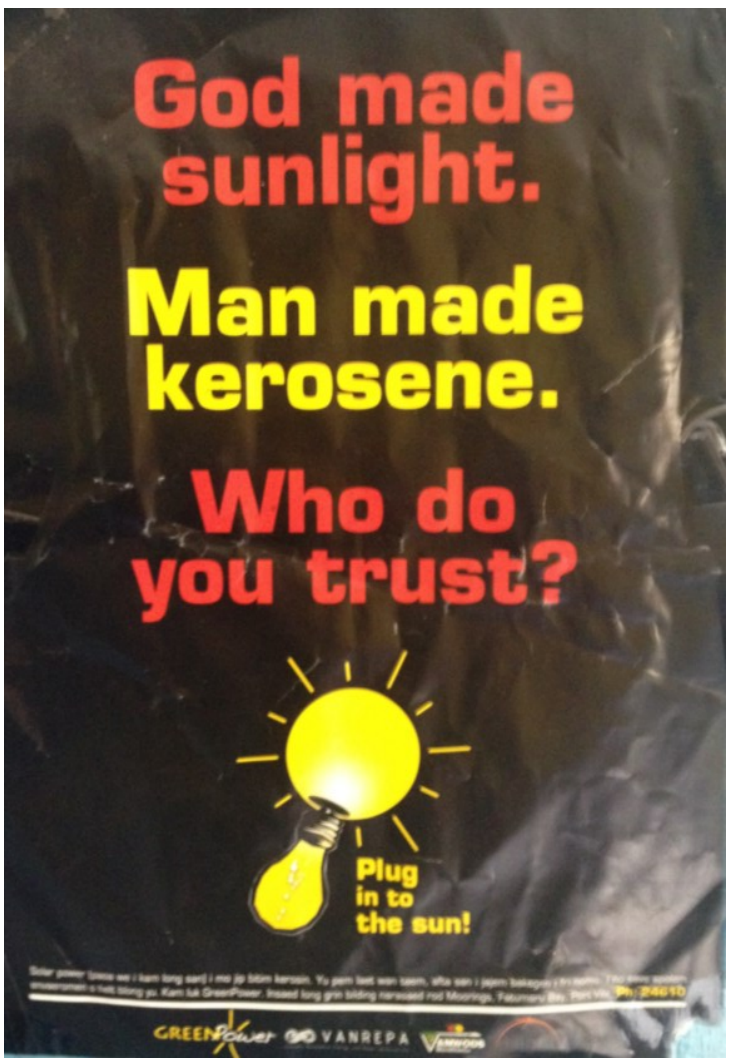

The aspirations and expectations of achieving a solar powered future was not limited to portable solar lighting. As awareness of solar powered lighting had exploded since the start of the Lighting Vanuatu programme, the expectation from many of the villages visited was that the future will be increasingly solar, which would include larger housing systems as well as the convenient and mobile portable solar lights. This future expectation is expressed by a young father from Laukatai who, when asked how he disposed of an earlier broken solar light, stated "I want to keep it as a memory [the solar light]. When my kids get older I want to show them what we used to use for light." 
This is a peer-reviewed, accepted author manuscript of the following research article: Walton, S., \& Ford, R. (2020). Easy or arduous? Practices, perceptions and networks driving lighting transitions from kerosene to solar in Vanuatu. Energy Research and Social Science, [101449]. https://doi.org/10.1016/j.erss.2020.101449

\subsubsection{Competence and skills needed for the practice of solar lighting}

For lighting to work, people need to be able to use the appropriate technology with a certain competence. The most commonly heard reaction to the lights in our field research was that they were 'easy', meaning that the competence needed for the practice of lighting in Vanuatu was not complicated - indeed we were told "you just press the button." For a practice to become embedded in everyday life it needs to be convenient $\left[{ }^{55}\right]$, and we found that in this rapid transition it went beyond just being convenient to being 'easy'. The competence level of the practice is important to understand in the development of the practice itself. The following section expands on this.

Solar lights were found to be better suited than the kerosene lamps for supporting existing household practices; they are easier to operate, brighter, do not have a flame that could blow out, there is no danger of causing fire, they do not generate heat and they are safer to carry around. As well as supporting existing practices, solar lighting has also had an impact on the purposes for which the lights are used, on the levels of social interaction and on which members of the household are able to use the lights. The following subsections represent the ways in which 'easy' was discussed by participants.

\section{'Easy' in the everyday}

The most prominent discussion across the interviews and focus groups was how the solar lights made everyday life easier. The patterns of use and stories told varied little between villages, and examples discussed by participants include:

- Mothers getting up during the night for babies or sick children find it much easier to turn on the solar light than light a candle. 
This is a peer-reviewed, accepted author manuscript of the following research article: Walton, S., \& Ford, R. (2020). Easy or arduous? Practices, perceptions and networks driving lighting transitions from kerosene to solar in Vanuatu. Energy Research and Social Science, [101449]. https://doi.org/10.1016/j.erss.2020.101449

- Some of the older members of the community mentioned that it made it easier to go to the toilet at night.

- Other tasks such as fetching water, kava preparation, weaving mats, sewing dresses, doing homework, conducting meetings (often there would be a number of lights at a meeting), fishing at night, and going to church at night were also made easier.

- In a focus group in Laukatai it was mentioned that there was no more collecting firewood, no lighter required and no kerosene needed, which made the everyday lighting of the household easier.

\section{Easy because the lights are not complicated technology}

Solar lamps required little education to use; as one participant mentioned, “Just press the button!' The word 'easy' was never associated with solar panels and observational evidence suggests that the level of involvement here was anything but easy. However, the concept of easy was associated with other technology such as mobile phones as we found with an advertising campaign - "making mobile easy" - an attempt to de-mystify the concept of a mobile phone to encourage uptake of this technology. For many people (Ni Vanuatu and globally too) mobile phones themselves and the wider technologies with the phone i.e. the call plans, top ups, texting etc. may be off-putting for purchase. Therefore, the technologies (methods around the technology) and the piece of technology itself (material culture) have to be easy to adopt for uptake to occur. The same happened with the solar lights, participants told stories of seeing other villagers with the lights and seeing how easy they were to operate and then realising that the lights would benefit them as well and be easy to operate and use in everyday life. 
This is a peer-reviewed, accepted author manuscript of the following research article: Walton, S., \& Ford, R. (2020). Easy or arduous? Practices, perceptions and networks driving lighting transitions from kerosene to solar in Vanuatu. Energy Research and Social Science, [101449]. https://doi.org/10.1016/j.erss.2020.101449

\section{Easy because they are mobile}

Numerous comments were made describing the ways in which the mobility of the lights made everyday life easier too. For example, former Provincial Council President Mr. Yatasaimaka noted that even though his village was connected to the grid, electricity is fixed, the solar lights are mobile. He gave examples of how he uses the lights which include, going fishing at night, digging for kava and looking for shellfish. Another example given from Tanna was of the lights being used when inter-village events are being held. The lights are taken with them to other villages and used there in the preparation of food and then are also useful for the walk home in the dark. These examples provided by participants illustrate the ways in which the mobility of the solar lights help to make their current lifestyle easier.

\section{Easy because they are safer}

Included in the theme of 'easy' are a number of comments from participants that discuss the solar lights being safer. Villagers from Middle Bush in the Island of Tanna talked about how much easier and safer they were during cyclone time. Vanuatu can be subject to strong winds, especially during the cyclone season, and quite a few participants mentioned that they found the lights safer and easier to use during these times; the solar lights were preferred to kerosene lamps for their activities because they were found to be brighter and because there was no flame to blow out in any wind. Wind was mentioned a few times in terms of how much safer the solar lights are when there is wind. There were also comments made about the burning of houses and how the solar lights were much safer. Another example of participants mentioning the lights being safe was a conversation with two young males on the Island of Tanna who were very keen on solar energy despite being in a grid connected village. They emphasised safety as a key feature of solar for two reasons: (1) Older members 
This is a peer-reviewed, accepted author manuscript of the following research article: Walton, S., \& Ford, R. (2020). Easy or arduous? Practices, perceptions and networks driving lighting transitions from kerosene to solar in Vanuatu. Energy Research and Social Science, [101449]. https://doi.org/10.1016/j.erss.2020.101449

of the community were noted as often being "afraid of electricity" and did not feel that electricity was a safe source of energy and often avoided using it and (2) Children can carry the solar lights around without any concern of setting the house on fire.

\section{Easy because the lights last longer}

People in the villages also mentioned the length of time that the solar lights lasted. Typically they could last all night if they had been charged during the day. As they were cheaper (free) to run, the length of time they were on was not monitored in the same way that a candle or kerosene lamp had been. Comments indicated that this gave a sense of freedom in terms of being able to just use them when they were needed and wanted.

With the change in lighting technology there has been increased opportunity for social interactions with the lights being used for village and inter-village functions. Women were able to take advantage of the new technology, using the solar lights to facilitate social working groups (e.g. mat weaving) in the evenings. In addition, children were able to comfortably use solar lights, whereas they were not able to use kerosene lamps due to the potential dangers of a naked flame. This ease of use has enabled them to use the lights to study at night, changing generational practices and influencing norms around energy use.

The main concern with the lights was whether they would get wet during the rainy season and stop working - there were sometimes stories from participants about this happening to someone whom they knew and then they would show concern. In a village we visited in Tanna the villagers showed us how they wrapped the lights when charging them to stop the condensation - they were finding ways of adapting the technology to the physical environs. Others found dry places to hang the lights for charging during wet days where the lights themselves would not get wet. Another story we heard involved sending children back 
This is a peer-reviewed, accepted author manuscript of the following research article: Walton, S., \& Ford, R. (2020). Easy or arduous? Practices, perceptions and networks driving lighting transitions from kerosene to solar in Vanuatu. Energy Research and Social Science, [101449]. https://doi.org/10.1016/j.erss.2020.101449

to the village from the garden to rescue a light when it had started raining. Hence, while there were some limitations of the technology and issues with charging we found that ways of dealing with the issues were being created at the village level and adapted into everyday practices and routines.

From an energy transition point of view this is a useful finding - it shows that if the technology is easy to use and aligns with existing meanings and norms and makes daily life more convenient, a rapid uptake can be enabled. The future trajectory of energy and lighting in Vanuatu would seem to be solar; not only have solar lights become normalised in the everyday, there are also high expectations that solar powered energy will light the way towards a better and more convenient future in rural Vanuatu.

\subsubsection{Distribution and Institutions supporting the solar lighting practice}

One of the main findings from the study was around the ease with which solar lamps could be purchased and used due to the NGOs involved in the project successfully tapping into existing distribution channels. For example, participants explaining how they bought the lights:

"[The NGO lady] sold some lights so we looked and wanted to buy one." (Anduan 1)

"Youth challenge made an awareness and introduced the light to the village." (Epau 4)

"It was introduced to us by Youth Challenge [the distributor for VANREPA] and we also saw them at the Chinese shops [in Port Vila].” (Emua 1)

The distribution approach taken in the Lighting Vanuatu program made the process of purchasing the lights easy, despite the challenges with distributing across a large number of 
This is a peer-reviewed, accepted author manuscript of the following research article: Walton, S., \& Ford, R. (2020). Easy or arduous? Practices, perceptions and networks driving lighting transitions from kerosene to solar in Vanuatu. Energy Research and Social Science, [101449]. https://doi.org/10.1016/j.erss.2020.101449

islands and remote communities. One distributor took an approach of giving 50 lights to leaders in communities to facilitate the distribution of the lights. These leaders then ended up buying and paying for hundreds of lights and distributing them freely to households throughout their respective communities. As interpersonal communication channels are key to enable widespread uptake of new technologies $\left[{ }^{56}\right]$, this approach may have spearheaded further uptake of the lights by families who may have not otherwise considered them.

Another distributor described a two-fold approach. The first part of his approach involved sending individual staff to rural communities to either act as a travelling agent selling lights to the communities directly, or to set up shop as a local retailer on the island. The second part included promoting his campaign for solar energy on National Radio to encourage those on the islands to get in contact with their family in Port Vila to send/bring back lights to the villages. Both these approaches were purported to have yielded successful results for his business.

One of the NGOs involved in the distribution of the lights created a microfinance agreement with the local Telco. This partnership was initiated because the solar light included a charger for mobile phones, which added to the commodity's usefulness in the villages. The microfinance was for both a mobile phone and solar light/charger and involved a scheme for people to pay off their phones and solar lights as a package. This finance package was popular with some participants but the majority with whom we spoke saved money by selling items at the market to purchase the solar lights as a one-off payment.

\subsubsection{Repair and maintenance}

While repair and maintenance issues can be critical to ensuring prolonged adoption and use of solar technology $\left[{ }^{57} 58\right]$, this was not a key issue emerging from the interview and 
This is a peer-reviewed, accepted author manuscript of the following research article: Walton, S., \& Ford, R. (2020). Easy or arduous? Practices, perceptions and networks driving lighting transitions from kerosene to solar in Vanuatu. Energy Research and Social Science, [101449]. https://doi.org/10.1016/j.erss.2020.101449

observational work. In some of the villages visited, participants talked about how members of the local community had repaired lamps that had broken, sometimes by combining the "working" parts from multiple lamps. They also discussed issues around quality, noting that the quality of the lamps sold by the NGOs involved in the Lighting Vanuatu programme was superior to the lamps bought from the Chinese shops on the mainland, some of which would break within a few days of being purchased.

Data from the survey supported the interviews and observations; $17.9 \%$ of respondents had to get their solar light repaired and of these, $38.5 \%$ did it themselves, $29.7 \%$ employed local tradesmen (29.7\%) and 20.3\% took it back to the place of purchase. Although repair and maintenance is clearly an issue, it is not one that discouraged the use of the lamps, given that the fieldwork occurred almost two years after the programme ended (though solar lamps continued to be distributed after this time), and indeed an entire year after the survey data had been collected.

\subsection{Systems of practice}

The above sections have dealt with each aspect of the practice of lighting in rural Vanuatu separately, the aim of this section is to combine the aspects to understand the "circuit of production and reproduction" $\left[{ }^{59}\right]$. The following figure illustrates this: 
This is a peer-reviewed, accepted author manuscript of the following research article: Walton, S., \& Ford, R. (2020). Easy or arduous? Practices, perceptions and networks driving lighting transitions from kerosene to solar in Vanuatu. Energy Research and Social Science, [101449]. https://doi.org/10.1016/j.erss.2020.101449

Figure 4: System of portable lighting practice in Vanuatu

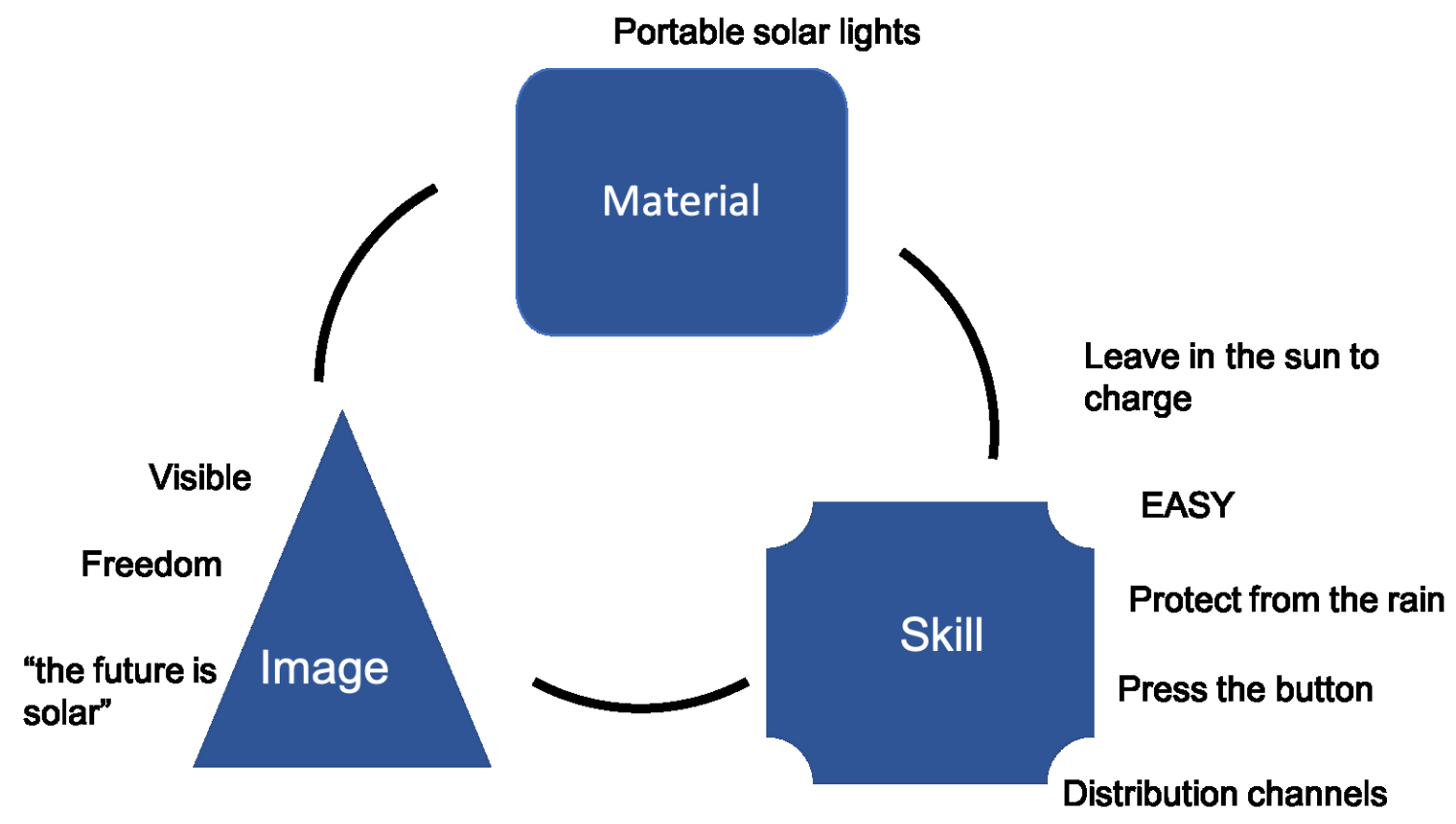

The material change explored was a transition from largely kerosene lighting to portable solar lights. This was a change in "stuff" [ $\left[{ }^{60}\right]$ (Schatzki, 2010:125) in terms of the materiality of what the villagers use to produce light. However, the practice of lighting is much more than just the material technology that physically produces the light. Drawing on Shove and Pantzar's work ${ }^{4}$ and Hargreaves et al.[ $\left[{ }^{61}\right.$ we suggest that the competence and the symbolic images of the solar lights together enable and produce this practice of lighting in Vanuatu. The above combination is demonstrated by the solar lights being so easy to operate and easy in terms of supporting other aspects of daily lifestyle e.g removing the need for constant purchase of kerosene in a cash/subsistence economy or supporting mothers in the middle of the night when tending to her baby.

\footnotetext{
${ }^{4}$ https://www.lancaster.ac.uk/staff/shove/choreography/table.htm
} 
This is a peer-reviewed, accepted author manuscript of the following research article: Walton, S., \& Ford, R. (2020). Easy or arduous? Practices, perceptions and networks driving lighting transitions from kerosene to solar in Vanuatu. Energy Research and Social Science, [101449]. https://doi.org/10.1016/j.erss.2020.101449

The symbolic meanings of the lights further add to the system and reproduction of practice. The lights signify progress and freedom to the participants. The lights enable other practices to happen much more easily which in turn leads participants to see the lights as representing progress and the future. Therefore, the ease of the system of practice surrounding the lights - easy to use, easy to obtain and symbolically presenting a future that is easier, was influential in the construction of the new practice which now reproduces the wider system of practices, with cultural infrastructures of Vanuatu being part of this wider system.

However, care must be taken when considering the impact of the cultural context on the wider replicability or scalability of such a transition. In this study the importance of "easy" appears to have been key to driving such a rapid transition, and while this may be in part related to the technology shift, it is also in part due to the underlying cultural context in which this shift has emerged. As depicted in Figure 5, the concept of "easy" fits well with the NiVanuatu culture, and as such the finding relating to "easy" must be understood in respect of the ease with which the solar lighting technology could be adopted into existing practices, as well as the underlying aspirations for "easy" in the wider cultural context. 
This is a peer-reviewed, accepted author manuscript of the following research article: Walton, S., \& Ford, R. (2020). Easy or arduous? Practices, perceptions and networks driving lighting transitions from kerosene to solar in Vanuatu. Energy Research and Social Science, [101449]. https://doi.org/10.1016/j.erss.2020.101449

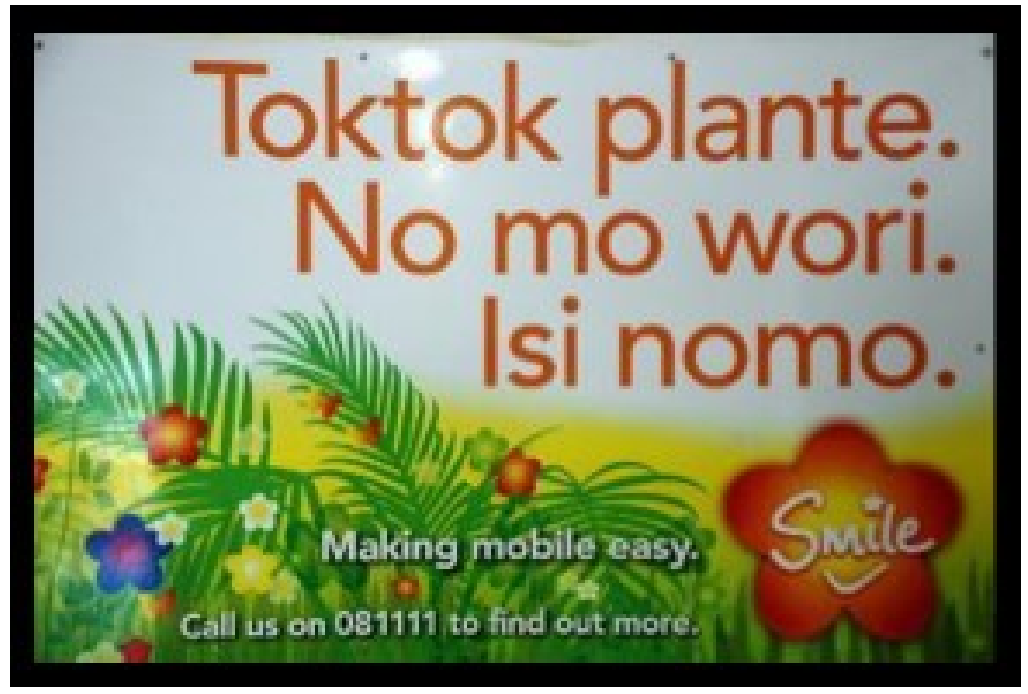

Figure 5: Telecom Vanuatu Limited's (TVL) "Making mobile easy" campaign, Port Vila Bauerfield domestic Airport

The practices of circulation between islands and social interactions between and within communities enabled the solar light technology to be effectively distributed throughout the many small islands. The supply chain was a cultural infrastructure and, by tapping into that, the NGOs were able to circulate the solar lights and knowledge of them widely. Therefore, accounting for the wider infrastructural layer has been key in our understanding of practices that gave rise to the rapid socio-technical transition in Vanuatu. The ease with which systems of practice changed as a result of the introduction of the lights in this manner, meant that not only did sales of the lights continue to escalate, but that the landscape shifted and solar became embedded into the norms and patterns of thought (images) for lighting and energy in Vanuatu.

\section{Conclusion: Enabling Technological Shifts}

Examining the lighting Vanuatu project has enabled an in-depth look at how a rapid change in technology in a developing country has occurred. Using data from surveys and 
This is a peer-reviewed, accepted author manuscript of the following research article: Walton, S., \& Ford, R. (2020). Easy or arduous? Practices, perceptions and networks driving lighting transitions from kerosene to solar in Vanuatu. Energy Research and Social Science, [101449]. https://doi.org/10.1016/j.erss.2020.101449

interviews conducted throughout Vanuatu we have been able to explore the practice of solar lighting and identify some of the key elements that have enabled this rapid transition.

First, cutting across all the elements of lighting practice we identified that the solar lighting technology was easy - easy to use, easy to obtain and easy in terms of how it made existing household practices easier. While it was interesting to see potential correlations between easiness and uptake, we questioned whether 'easy' is indeed a finding? However, due to the dominance of this word across participant transcripts, we believe that it is a crucial finding.

Being easy extends to symbolic meanings and, in particular, participants' expectations, aspirations and cultural context. We found that people discussed a future with bigger and brighter solar; they did not want to return to kerosene and instead wanted more solar technology. Indeed, we heard stories of people returning from seasonal work programmes in New Zealand with solar lights and solar panels for themselves and others in their village, which is exciting from an energy transition perspective as the solar transition is represented in their aspirations for the future. Symbolically, solar is perceived to be progress and the future for the villages.

In addition to the elements of the practice of lighting, this research also considered the role of institutions, distribution and the informal networks (i.e. the infrastructure) that facilitated the distribution of the lights throughout most of Vanuatu. From a transitory perspective, the networks that enabled this technology to go far and wide was significant in the success of the project. We learnt that the networks already existed and the NGOs cleverly drew upon these networks to bring about this transition and make it easy to obtain the solar lights. Networks and the community are a part of Ni Vanuatu culture $\left[{ }^{62}\right]$. This technology 
This is a peer-reviewed, accepted author manuscript of the following research article: Walton, S., \& Ford, R. (2020). Easy or arduous? Practices, perceptions and networks driving lighting transitions from kerosene to solar in Vanuatu. Energy Research and Social Science, [101449]. https://doi.org/10.1016/j.erss.2020.101449

became part of the existing networks; it did not alienate, but rather integrated into the circulation and community that already existed, and from stories we heard of village life, the lights were also used frequently in communal village activities - perhaps because they just made it easy! Therefore, we suggest that practice systems are embedded in wider practice systems that also need to be understood for transitions or changes to practices to occur. Future studies could explore similar transitions in other developing small island states or look to different types of states to see if similar aspects at the practice level are important for the transition.

Further work might also benefit from considering how these practice level aspects might support or inhibit wider sociotechnical shifts. While "easy" has been a key element in the transition from kerosene to solar lamps, it is not clear how important this would be when considering further solar adoption, such as the uptake of solar panels. This is a slightly different question because the solar panels are not replacing an existing technology in providing an energy service (lighting), but are instead providing a new technology to deliver new energy services (e.g. use of computers and televisions, refrigeration, etc.). Despite these differences, it would be interesting to explore whether "easy" is a defining factor in this transition (e.g. ease of purchase, installation, use, maintenance) and the impact this may have in terms of the longevity of the solar industry and the requirements for new skills development.

Finally, this study contributes towards research on sustainable transitions. This study focuses attention on transitions emerging from shifts in practice as well as shifts in technology, and adds a consumer voice to the literature - giving an understanding and perspective from those actors in the system who are driving the socio-technical transition and 
This is a peer-reviewed, accepted author manuscript of the following research article: Walton, S., \& Ford, R. (2020). Easy or arduous? Practices, perceptions and networks driving lighting transitions from kerosene to solar in Vanuatu. Energy Research and Social Science, [101449]. https://doi.org/10.1016/j.erss.2020.101449

changing the landscape. In addition, and importantly, this adds mixed method primary data to the field of transitions - another gap in the area. Finally, we argue for paying close attention to context - to understand transitions in their context, and for context to be a key part of decision making and planning for successful transitions. Therefore, this case of a rapid transition of lighting in Vanuatu shows the importance of understanding the practice level to be able to plan successfully for a sustainable transition and points to the need for transitions to be positive easy processes for consumers - or pitched as such, in order to change systems of practice in transitioning societal systems.

${ }^{1}$ Dornan, M. \& Cain, T.N. (2014). Regional service delivery among Pacific Island countries: An assessment. Asia and the Pacific Policy Studies (APPS). 1(3) 541-560.

2 Apple, J., Vicente, R., Yarberry, A., Lohse, R., Mills, E., Jacobson, A., Poppendieck, D. (2010). Characterization of particulate matter size distributions and indoor concentrations from kerosene and diesel lamps. Indoor Air, 20 (5) 399-411.

${ }^{3}$ Lam, N. L., Smith, K. R., Gauthier, A., \& Bates, M. N. (2012). Kerosene: a review of household uses and their hazards in low-and middle-income countries. Journal of Toxicology and Environmental Health, Part B, 15(6), 396-432.

${ }^{4}$ Balakrishnan, K., Cohen, A., \& Smith, K. R. (2014). Addressing the burden of disease attributable to air pollution in India: the need to integrate across household and ambient air pollution exposures. Environmental Health Perspectives, 122 (1) A6-7.

${ }^{5}$ Mills, E. (2016). Identifying and reducing the health and safety impacts of fuel-based lighting. Energy for Sustainable Development, 30 (Feb): 39-50.

${ }^{6}$ Landrigan, P. J., Fuller, R., Acosta, N. J., Adeyi, O., Arnold, R., Baldé, A. B., ... \& Chiles, T. (2018). The Lancet Commission on pollution and health. The Lancet, 391(10119), 462-512.

${ }^{7}$ Negro, S.O., Alkemade, F., \& Hekkert, M.P. (2012). Why does renewable energy diffuse so slowly? A review of innovation system problems. Renewable and Sustainable Energy Reviews, 16 (6): 3836-3846.

${ }^{8}$ Boamah, F., \& Rothfuß, E. (2018). From technical innovations towards social practices and socio-technical transition? Re-thinking the transition to decentralised solar PV electrification in Africa. Energy Research and Social Science, 42 (March), 1-10

${ }^{9}$ Ulsrud, K., Rohracher, H., Winther, T., Muchunku, C., \& Palit, D. (2018). Pathways to electricity for all: What makes village-scale solar power successful? Energy Research and Social Science, 44 (September 2017), 32-40. https://doi.org/10.1016/j.erss.2018.04.027 
This is a peer-reviewed, accepted author manuscript of the following research article: Walton, S., \& Ford, R. (2020). Easy or arduous? Practices, perceptions and networks driving lighting transitions from kerosene to solar in Vanuatu. Energy Research and Social Science, [101449]. https://doi.org/10.1016/j.erss.2020.101449

${ }^{10}$ Shove, E., \& Walker, G. (2007). CAUTION! transitions ahead: politics, practice and sustainable transition management. Environment and Planning A, 39: 763-770.

${ }^{11}$ Kumar, A., Ferdous, R., Luque-Ayala, A., McEwan, C., Power, M., Turner, B., \& Bulkeley, H. (2019). Solar energy for all? Understanding the successes and shortfalls through a critical comparative assessment of Bangladesh, Brazil, India, Mozambique, Sri Lanka and South Africa. Energy Research and Social Science, 48(March 2018), 166-176. https://doi.org/10.1016/j.erss.2018.10.005

${ }^{12}$ Walton, S., Doering, T.A., Gabriel, C., \& Ford, R. (2014). Energy Transitions: Lighting in Vanuatu. Report commissioned by The Australian Agency for International Development: Canberra, Australia.

${ }^{13}$ Kumar, R., \& Igdalsky, L. (2019). Sustained uptake of clean cooking practices in poor communities: Role of social networks. Energy Research Social Science, 48 (2019) 189-193.

${ }^{14}$ DEFRA quoted in Shove, E. (2010). Beyond the ABC: Climate change policy and theories of social change. Environmental. Planning A, 42 (2010) 1273-1285 pp 1276.

${ }^{15}$ Shove, E., \& Walker, G. (2010). Governing transitions in the sustainability of everyday life. Research Policy, 39 (4):471-476 pp

${ }^{16}$ Shove, E., Watson, M.T. , \& N. Spurling, N. (2015). Conceptualising connections: Energy demand, infrastructures and social practices. European Journal of Social Theory, 18 (3) pp

${ }^{17}$ Spaargaren, G. (2003). Sustainable consumption: a theoretical and environmental policy perspective. Society \& Natural Resources, 16(8), 687-701.

${ }^{18}$ Shove, E. (2010). Beyond the ABC: Climate change policy and theories of social change. Environmental. Planning A, 42 (2010) 1273-1285.

${ }^{19}$ Shove, E., Watson, M.T. , \& N. Spurling, N. (2015). Conceptualising connections: Energy demand, infrastructures and social practices. European Journal of Social Theory, 18 (3).

${ }^{20}$ Watson, M. (2012). How theories of practice can inform transition to a decarbonised transport system. Journal of Transport Geography. 24 (Sep): 488-496.

${ }^{21}$ Spurling, N. J., McMeekin, A., Southerton, D., Shove, E. A., \& Welch, D. (2013). Interventions in practice: reframing policy approaches to consumer behaviour. Sustainable Practices Research Group Report, England

${ }^{22}$ Shove, E. (2010). Beyond the ABC: Climate change policy and theories of social change. Environmental. Planning A, 42 (2010) 1273-1285.

${ }^{23}$ Bourdieu, P. (1977). Outline of a Theory of Practice. Cambridge University Press, Cambridge, UK.

${ }^{24}$ Giddens, A. (1984). The Constitution of Society. University of California Press, Berkeley, 1984.

${ }^{25}$ Giddens, A. (1991). Structuration theory. Past, present and future, in: C. Bryant, D. Jarg (Eds.), Giddens' Theory of Structuration: A Critical Appreciation. Routledge, London.

${ }^{26}$ Schatzki, T. R. (2010). The Timespace of Human Activity: On Performance, Society, and History as Indeterminate Teleological Events, Lanham: Lexington.

${ }^{27}$ Reckwitz, A. (2012). Affective spaces: a praxeological outlook, Rethinking History, 16 (2): 241-258. 
This is a peer-reviewed, accepted author manuscript of the following research article: Walton, S., \& Ford, R. (2020). Easy or arduous? Practices, perceptions and networks driving lighting transitions from kerosene to solar in Vanuatu. Energy Research and Social Science, [101449]. https://doi.org/10.1016/j.erss.2020.101449

${ }^{28}$ Reckwitz, A. (2012). Toward a theory of social practices: a development in culturalist theorizing, European Journal of Social Theory, 5 (2): 243-263.

${ }^{29}$ Latour, B. (2005). Reassembling the Social-An Introduction to Actor-Network Theory, Oxford University Press, Oxford.

${ }^{30}$ Warde, A. (2005). Consumption and theories of practice, Journal of Consumer Culture, 5 (2): 131-153.

${ }^{31}$ Shove, E., \& Spurling, N. (2013). Sustainable Practices: Social Theory and Climate Change, Routledge, Abingdon.

${ }^{32}$ Strengers, Y., Moloney, S., Maller, C. \& Horne, R. (2015). Beyond Behaviour Change: Practical Applications of Social Practice Theory in Behaviour Change Programmes, Routledge, New York.

${ }^{33} \mathrm{Du}$ Gay, P. (1996). Consumption and Identity at Work. Sage: London.

${ }^{34}$ Du Gay, P. (1996). Consumption and Identity at Work. Sage: London.

${ }^{35}$ Du Gay, P., Hall, S., Janes, L., Madsen, A. K., Mackay, H., \& Negus, K. (2013). Doing Cultural Studies: The story of the Sony Walkman. Sage: London.

${ }^{36}$ Shove, E., \& Pantzar, M. (2005). Consumers, producers and practices understanding the invention and reinvention of Nordic walking, Journal of Consumer Culture, 5 (10: 43-6.

${ }^{37}$ Shove, E., \& Pantzar, M. (2005). Consumers, producers and practices understanding the invention and reinvention of Nordic walking, Journal of Consumer Culture, 5 (10: 43-6.

${ }^{38}$ Shove, E., \& Walker, G. (2010). Governing transitions in the sustainability of everyday life. Research Policy, 39 (4):471-476.

${ }^{39}$ Shove, E. (2003). Converging conventions of comfort, cleanliness and convenience. Journal of Consumer Policy, 26 (4): 395-418.

${ }^{40}$ Chappells, H. \& Shove, E. (2005). Debating the future of comfort: environmental sustainability, energy consumption and the indoor environment. Building Research and Information, 33(1) pp32-40.

${ }^{41}$ Shove, E., \& Walker, G. (2007). CAUTION! transitions ahead: politics, practice and sustainable transition management. Environment and Planning A, 39: 763-770.

${ }^{42}$ Schatzki, T. R. (2010). The Timespace of Human Activity: On Performance, Society, and History as Indeterminate Teleological Events, Lanham: Lexington.

${ }^{43}$ Fetterman, D.M. (1989). Ethnography: Step-by-Step. Sage: Newhury Park, Califomia.

${ }^{44}$ Geertz, C. (1973). The Interpretation of Cultures. Basic Books, Inc., (Vol. 5019). New York.

${ }^{45}$ Geertz, C. (1973). The Interpretation of Cultures. Basic Books, Inc., (Vol. 5019). New York., pp6.

${ }^{46}$ Rabinow, P., \& Sullivan, W.M. (1979). Interpretive Social Science: A reader. University of California Press: Berkeley, pp20.

${ }^{47}$ Kondo, D.K. (1990). Crafting Selves: Power, Gender, and Discourses of Identity in a Japanese Workplace, University of Chicago Press: Chicago.

${ }^{48}$ Fetterman, D.M. (1989). Ethnography: Step-by-Step. Sage: Newhury Park, Califomia. 
This is a peer-reviewed, accepted author manuscript of the following research article: Walton, S., \& Ford, R. (2020). Easy or arduous? Practices, perceptions and networks driving lighting transitions from kerosene to solar in Vanuatu. Energy Research and Social Science, [101449]. https://doi.org/10.1016/j.erss.2020.101449

${ }^{49}$ Emerson, R.M., Fretz, R.I. \& Shaw, L.L. (1995). Writing Ethnographic Fieldnotes. University of Chicago Press: Chicago.

50 Shove, E., \& Pantzar, M. (2005). Consumers, producers and practices understanding the invention and reinvention of Nordic walking, Journal of Consumer Culture, 5 10: 43-6.

${ }^{51}$ Foucault, M. (2002[1972]). The Archaeology of Knowledge. Translated from the french by AM Sheridan Smith, Pantheon Books, London: Routledge.

${ }^{52}$ Laclau, E., \& Mouffe, C. (2001). Hegemony and Socialist Strategy: Towards a Radical Democratic Politics. Second ed., Verso: London

${ }^{53}$ Shove, E., \& Walker, G. (2010). Governing transitions in the sustainability of everyday life. Research Policy, 39 (4):471-476 pp472.

54 Taylor, J.P. (2008). The Other Side: Ways of Being and Place in Vanuatu, University of Hawaii Press: Honolulu, pp21.

55 Shove, E. (2003). Converging conventions of comfort, cleanliness and convenience. Journal of Consumer Policy, 26 (4): 395-418.

56 Taylor, J.P. (2008). The Other Side: Ways of Being and Place in Vanuatu, University of Hawaii Press: Honolulu,

${ }^{57}$ Hills, J.M., Michalena, E., Chalvatzis, K.J. (2018). Innovative technology in the Pacific: Building resilience for vulnerable communities. Technological Forecasting and Social Change, 129: 16-26.

${ }^{58}$ Cross, J., \& Murray, D. (2018). The afterlives of solar power: Waste and repair off the grid in Kenya. Energy Research and Social Science, 44(August 2017), 100-109. https://doi.org/10.1016/j.erss.2018.04.034

${ }^{59}$ Hargreaves, T., Haxeltine, A., Longhurst, N., \& Seyfang, G. (2011). Sustainability transitions from the bottom-up: Civil society, the multi-level perspective and practice theory (No. 2011-01). CSERGE Working Paper pp8.

${ }^{60}$ Schatzki, T. R. (2010). The Timespace of Human Activity: On Performance, Society, and History as Indeterminate Teleological Events, Lanham: Lexington pp225.

${ }^{61}$ Hargreaves, T., Haxeltine, A., Longhurst, N., \& Seyfang, G. (2011). Sustainability transitions from the bottom-up: Civil society, the multi-level perspective and practice theory (No. 2011-01). CSERGE Working Paper.

62 Taylor, J.P. (2008). The Other Side: Ways of Being and Place in Vanuatu, University of Hawaii Press: Honolulu. 